\title{
Clinical Trial Financial Agreement
}

National Cancer Institute

\section{Source}

National Cancer Institute. Clinical Trial Financial Agreement. NCI Thesaurus. Code C115475.

A legally binding document that contains the provisions governing financial compensation between the trial sponsor, and any institutions, departments, or individuals participating in the trial. 